\title{
Nifedipine Blocks Effects of Triazolam Injected into the Dorsal Raphe Nucleus on Sleep
}

Wallace B. Mendelson, M.D.

In previous studies, the author has reported both in vitro and in vivo sleep studies in which there were complex interactions between benzodiazepine hypnotics and the dihydropyridine calcium channel blocker nifedipine. The author has also reported that microinjections of triazolam into the dorsal raphe nucleus of the rat result in enhancement of wakefulness. In the present study, nifedipine and triazolam were coadministered into this site. As previously was observed, triazolam produced a dose-dependent increase in sleep latency and a decrease in total sleep, primarily by reducing non-rapid-eyemovement sleep. Nifedipine had no effect on sleep when given by itself but prevented the alterations in sleep by triazolam. These various sleep effects were not associated with alterations in core temperature. These data are consistent with the view that some aspect of the sleepaltering activity of triazolam involves interaction with voltage-dependent calcium channel activity. [Neuropsychopharmacology 10:151-155, 1994]
KEY WORDS: Triazolam; Dorsal raphe; Sleep; Hypnotics

In an ongoing series of studies, this laboratory has characterized the interaction of benzodiazepines with the dihydropyridine calcium channel blocker nifedipine. Nifedipine administered intraventricularly was found to prevent the sleep-inducing properties of flurazepam administered systemically (Mendelson et al. 1984), whereas BAY K 8644, a dihydropyridine that enhances voltage-dependent calcium channel function, potentiates flurazepam (Mendelson et al. 1986; Mendelson, 1992). This phenomenon appears to occur after microinjection of benzodiazepines as well, insofar as nifedipine prevents sleep enhancement by triazolam when both are injected into the medial preoptic area (Mendelson and Monti 1992). Similarly, nifedipine has

From the Department of Neurology, The Cleveland Clinic Foundation, Cleveland, Ohio.

Address correspondence to: Wallace B. Mendelson, M.D., Department of Neurology, The Cleveland Clinic Foundation, 9500 Euclid Avenue, Desk S-51, Cleveland, Ohio 44195.

Received August 27, 1993; revised November 16, 1993 and December 20, 1993; accepted December 21, 1993. been reported to prevent alterations in uptake of calcium into synaptosomes induced by micromolar concentrations of diazepam (Mendelson et al. 1984). One implication of this work may be that the mechanism by which BZs enhance sleep may involve alteration of some subclass of voltage-dependent calcium channels. To explore this phenomenon further, we have now administered nifedipine in conjunction with triazolam at a CNS site at which microinjection of triazolam has been reported to reduce total sleep and enhance wakefulness, the dorsal raphe nucleus (Mendelson et al. 1987).

\section{MATERIALS AND METHODS}

\section{Animals and Animal Care}

The studies were performed on 13 male SpragueDawley albino rats weighing between 250 and 300 g purchased from Taconic Farms (Germantown, NY). After the surgical implantation of cannulae and electrodes (Mendelson et al. 1974), the rats were housed individually in smooth-walled plastic cages for at least 1 week prior to use in a study. The rats were housed the night 
before an experiment in the chambers in which they would subsequently be tested. Lights were on from 8:00 AM until 8:00 PM.

\section{Placement of Cannulae and Electrodes}

Each rat was anesthetized with $70 \mathrm{mg} / \mathrm{kg}$ ketamine and $6 \mathrm{mg} / \mathrm{kg}$ xylazine administered intramuscularly. The rat was then mounted in a Kopf stereotactic apparatus. After a scalp incision was made and the skull exposed, a hole was drilled at a stereotactically determined location. The dura was then gently disrupted at the hole and a 24-gauge stainless-steel guide cannula was lowered to $1.0 \mathrm{~mm}$ above the dorsal raphe. The stereotactic coordinates of the top of the guide cannula, derived originally from Paxinos and Watson (1986) and assessed from previous work and pilot studies, were as follows: $-8.4 \mathrm{~mm}$ anteroposterior, -4.3 dorsoventral, $1.5 \mathrm{~mm}$ mediolateral (the latter placed at an angle of $20^{\circ}$ from vertical to the skull in the coronal plane).

During the same surgical procedure, four $0-80$ stainless-steel screws were implanted through the skull to serve as dural EEG electrodes. These screws were connected to an Amphenol socket by short lengths of 0.010-inch Teflon-coated stainless-steel wire. The stripped ends of two other lengths of this wire were implanted in the neck musculature to act as electromyographic (EMG) electrodes and these, too, were connected to the Amphenol socket. Before releasing the rat from the stereotactic apparatus, the entire assembly of cannulae, electrodes, and Amphenol socket was cemented in place with dental acrylic.

\section{Intracranial Injections}

In this study, each animal received all six drug and vehicle combinations. Treatments were given on the basis of a modified Latin Square design, with studies separated by 1 week each. At 10:00 AM the morning of an experiment, an injection cannula of 31-gauge stainless steel tubing was inserted so that the tip extended precisely $1.0 \mathrm{~mm}$ past the tip of the guide cannula into the brain. The drug or vehicle (first warmed to $37^{\circ} \mathrm{C}$ ) was injected from a $10-\mu l$ Hamilton syringe through a length of PE 20 tubing attached to the injection cannula. The injection was made at a rate of $0.2 \mu \mathrm{l} / \mathrm{min}$, for a total volume of $0.4 \mu \mathrm{l}$, using a syringe pump, and the inner cannula was left in place for 30 seconds after each injection. In all cases, triazolam or its vehicle was given first, followed 5 minutes later by nifedipine or its vehicle.

Triazolam was dissolved in a 1:1 mixture of Emulphor polyoxyethylated vegetable oil and ethanol. Just prior to the injection, this solution was diluted 10 -fold with artificial cerebrospinal fluid $\left(0.5 \mathrm{mM} \mathrm{NaH} \mathrm{PO}_{4}\right.$, $0.25 \mathrm{mM} \mathrm{Na}_{2} \mathrm{HPO}_{4}, 0.4 \mathrm{mM} \mathrm{MgCl}, 0.65 \mathrm{mM} \mathrm{CaCl}_{2}$,
$3 \mathrm{mM} \mathrm{KCl}, 128 \mathrm{mM} \mathrm{NaCl}, 25 \mathrm{mM} \mathrm{NaHCO} 3$, and 250 $\mathrm{mg} / \mathrm{ml}$ bovine serum albumin, $\mathrm{pH}=7.4$ ). The two doses given were $0.25 \mu \mathrm{g}(0.73 \mathrm{nmol} / \mathrm{L})$ and $0.5 \mu \mathrm{g}(1.46$ $\mathrm{nmol} / \mathrm{L})$. Nifedipine was prepared by dissolving $40 \mathrm{mg}$ $(115 \mu \mathrm{mol} / \mathrm{L})$ in $300 \mu \mathrm{l}$ of distilled water and injected for a total dose of $16 \mu \mathrm{g}(46 \mathrm{nmol} / \mathrm{L})$.

\section{Electroencephalographic Recordings}

Following the injection of the drugs, each rat was placed back in its testing chamber and a cable to a Grass Model 78 polygraph was attached to the Amphenol connector on the rat's headset. Three traces representing bifrontal EEG frontooccipital EEG, and EMG were recorded for 2 hours for each rat. The paper speed was $10 \mathrm{~mm} / \mathrm{sec}$ and the vertical deflection of the pen was calibrated so that $1.0 \mathrm{~cm}$ signified an electrical potential of $50 \mu \mathrm{V}$.

After the 8-hour recording session, each rat was returned to individual housing, and subsequent tests of further drug treatment conditions were performed at weekly intervals, such that all animals received all treatments. The order of treatment administration was determined by randomly assigning each rat to one of six treatment sequences. At the end of the study, an analysis of variance was performed in which "sequence" was an independent variable and it was confirmed that it had no significant effect on sleep variables such as sleep latency and total sleep time.

At the end of the study, a single investigator (who was unaware of the treatment condition) classified each 30-second epoch as "waking," "non-rapid-eye-movement (non-REM) sleep," or "REM sleep" (Mendelson et al. 1974, 1978). The results were then tallied and reported in terms of parameters including sleep latency (time from drug injection until the first three consecutive 30-second epochs of sleep), REM latency (time from sleep onset until the first two consecutive epochs of REM sleep), non-REM sleep time, REM sleep time, total sleep time, and intermittent wakefulness (Mendelson et al. 1978).

\section{Measurement of Core Body Temperature}

The serotonergic system is involved in temperature regulation and, in turn, temperature regulation may have important effects on sleep (Nagel and Satinoff 1980; Szymusiak and Satinoff 1984). Thus, to examine the possibility that any drug effects on sleep are indirectly mediated by alterations in temperature, we have also followed core temperature using the MiniMitter system that includes a transmitter which is implanted intraperitoneally in the rat at the time of the surgical placement of the EEG electrodes. This transmitter sends out a signal that encodes temperature. A receiver is situated underneath each of the testing cages, 
and the signal is decoded at a personal computer. Thus, body temperature can be monitored on a constant basis in a freely moving animal.

\section{Histological Examination of Injection Accuracy}

After a rat completed all the weekly drug treatments and EEG recordings for a given experimental protocol, an injection of $400 \mathrm{mg} / \mathrm{kg}$ of sodium pentobarbital was given intraperitoneally, and the animal was perfused transcardially with $0.9 \% \mathrm{NaCl}$ followed by $4 \%$ formalin in $1.25 \% \mathrm{NaCl}$. The rat was decapitated, and the brain was removed and stored in the formalin solution. Brain sections (48- $\mu \mathrm{m}$ thick) were cut on a freezing microtome, mounted on slides, and stained with cresyl violet. The tip of the injection cannula track was then localized by light microscopy. Injection sites are shown in the Figure.

\section{Statistical Analysis}

Data were analyzed by an analysis of variance for repeated measures. In cases in which there were significant treatment effects, post-hoc analyses were performed with a Least Significant Difference Test.

\section{RESULTS}

\section{Sleep Variables}

As seen in Table 1, triazolam microinjections given with vehicle for nifedipine resulted in a dose-dependent decrease in sleep, as reflected in an increase in sleep latency and decrease in total sleep time. The latter was accounted for primarily by a decrease in non-REM sleep, with no significant effect on REM sleep or intermittent waking time (waking time after initial sleep onset).
Nifedipine given with vehicle for triazolam had no significant effects on sleep. When the two drugs were given in combination, however, nifedipine blocked all of triazolam's effects on sleep, and no variables differed from those of the control condition (vehicle for both drugs). Comparisons of the "triazolam + nifedipine" treatments were also made against the "triazolam + vehicle for nifedipine" condition by post-hoc testing, and once again nifedipine reversed triazolam effects on sleep latency (at the higher dose), total sleep, and non-REM sleep.

\section{Core Temperature}

A series of variables were examined, including baseline (30 minutes before injection), mean for the first hour, mean for 6 hours, the difference between the baseline and the mean for the 1st hour, the highest temperature in 6 hours, and time from injection until the highest temperature was reached. For two animals, there were technical difficulties with temperature data; values for the remaining 11 animals are found in Table 2. There were no significant drug effects on any temperature measure. Also shown Table 2 are the mean values for the ambient temperature, which was not significantly different across treatments.

\section{CONCLUSIONS}

These data confirm previous work (Mendelson et al. 1987), which indicated that microinjections of triazolam decrease total sleep time, primarily by decreasing non-REM sleep. They are consistent with previous reports of increased motor activity after injections of benzodiazepines into the median raphe (Sainati and Lorens 1982). Systematic injections of benzodiazepines

Table 1. Effects of Microinjections of Triazolam and Nifedepine into the Dorsal Raphe Nucleus in 13 Subjects

\begin{tabular}{lccccccc}
\hline & $\begin{array}{c}\mathbf{V}_{\text {triaz }}+ \\
\mathbf{V}_{\text {nifed }}\end{array}$ & $\begin{array}{c}\text { triaz .25 } \\
\mathbf{V}_{\text {nifed }}\end{array}$ & $\begin{array}{c}\text { triaz .5 } \\
\mathbf{V}_{\text {nifed }}\end{array}$ & $\begin{array}{c}\mathbf{V}_{\text {triaz }}+ \\
\text { nifed }\end{array}$ & $\begin{array}{c}\text { triaz .25 } \\
\text { nifed }\end{array}$ & $\begin{array}{c}\text { triaz .5 }+ \\
\text { nifed }\end{array}$ & $\begin{array}{c}\text { ANOVA } \\
\text { ANO }\end{array}$ \\
\hline Sleep Latency & $22.8 \pm 2.5$ & $38.4 \pm 3.3^{\ddagger}$ & $43.8 \pm 4.2^{\ddagger}$ & $25.0 \pm 1.3$ & $27.5 \pm 4.0^{\|}$ & $29.5 \pm 3.7^{\star \star}$ & 0.001 \\
Total Sleep Time & $70.2 \pm 2.3$ & $61.0 \pm 4.7$ & $55.7 \pm 3.3^{\dagger}$ & $69.7 \pm 3.4$ & $62.5 \pm 4.4$ & $64.4 \pm 2.7 \S$ & 0.03 \\
REM Sleep & $4.7 \pm 0.85$ & $6.1 \pm 1.1$ & $4.0 \pm 0.9$ & $5.6 \pm 1.2$ & $3.3 \pm .82$ & $3.8 \pm 0.8$ & $\mathrm{NS}$ \\
NonREM Sleep & $65.0 \pm 2.4$ & $55.2 \pm 4.2^{\star}$ & $49.8 \pm 3.2^{\ddagger}$ & $65.6 \pm 3.1$ & $58.9 \pm 4.2$ & $60.2 \pm 2.9^{\star \star}$ & 0.01 \\
REM Latency & $49.7 \pm 7.5$ & $28.4 \pm 3.8$ & $45.2 \pm 4.3$ & $40.1 \pm 5.9$ & $44.6 \pm 10.5$ & $38.7 \pm 9.5$ & $\mathrm{NS}$ \\
Intermittent Waking Time & $28.2 \pm 2.0$ & $22.8 \pm 3.1$ & $23.3 \pm 2.5$ & $26.1 \pm 3.2$ & $31.6 \pm 3.8$ & $27.9 \pm 3.2$ & $\mathrm{NS}$ \\
\hline
\end{tabular}

* .05 compared to $V_{\text {triaz }}+V_{\text {nifed }}$ by Least Significance Difference (LSD) Test.

+01 compared to $V_{\text {triaz }}+V_{\text {nifed }}$ by LSD test.

$\ddagger .001$ compared to $V_{\text {triaz }}+V_{\text {nifed }}$ by LSD test.

$\$ .05$ compared to same dose of triazolam and vehicle for nifedipine.

$\| .01$ compared to same dose of triazolam and vehicle for nifedipine.

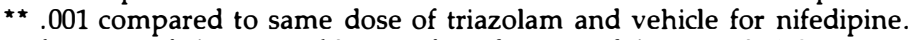

Definitions of sleep variables are found in Mendelson et al. (1978).

Abbreviations: triaz $.25=$ triazolam $.25 \mu \mathrm{g}$; triaz $.5=$ triazolam $.5 \mu \mathrm{g}$; nifed = nifedepine $16 \mu \mathrm{g}$; NS = not statistically significant; $\mathrm{ANOVA}=$ analysis of variance. All values represent mean $\pm \mathrm{SEM}$ minutes. 
Table 2. Core Temperature and Ambient Temperature Measures in 11 Subjects

\begin{tabular}{|c|c|c|c|c|c|c|c|}
\hline & $\begin{array}{c}\mathrm{V}_{\text {triaz }}+ \\
\mathrm{V}_{\text {nifed }}\end{array}$ & $\begin{array}{c}\operatorname{triaz} .25 \\
V_{\text {nifed }}\end{array}$ & $\begin{array}{c}\operatorname{triaz} .5 \\
\mathrm{~V}_{\text {nifed }}\end{array}$ & $\begin{array}{c}\mathrm{V}_{\text {triaz }}+ \\
\text { nifed }\end{array}$ & $\begin{array}{c}\text { triaz } .25 \\
\text { nifed }\end{array}$ & $\begin{array}{c}\text { traiz } .5 \\
\text { nifed }\end{array}$ & $p<$ \\
\hline$u r$ & \pm 1.51 & $.06 \pm 1.28$ & $35 \pm 1.30$ & \pm 1.55 & $.27 \pm 1.33$ & \pm 1.28 & NS \\
\hline Mean 6 hours & $40.78 \pm 1.61$ & $40.49 \pm 1.34$ & $40.30 \pm 1.26$ & $40.78 \pm 1.64$ & $40.35 \pm 1.14$ & $3 \pm 1.33$ & $N$ \\
\hline $\begin{array}{l}\text { Mean 1st hour - } \\
\text { baseline }\end{array}$ & $0.66 \pm 0.08$ & $0.75 \pm 1.56$ & $0.81 \pm 0.25$ & $1.23 \pm 0.51$ & $0.82 \pm 0.15$ & $4 \pm 0.22$ & NS \\
\hline Sleep onset & $40.60 \pm 1.08$ & $40.07 \pm 1.43$ & $40.32 \pm 1.33$ & $40.29 \pm 1.52$ & \pm 1.33 & $40.06 \pm 1.30$ & NS \\
\hline $\begin{array}{l}\text { Highest temperature } \\
\text { in } 6 \text { hours }\end{array}$ & $41.50 \pm 1$ & $41.25 \pm 1.36$ & $9 \pm 1.46$ & $6 \pm 1$ & $3 \pm 1.32$ & 48 & NS \\
\hline $\begin{array}{l}\text { Time from injection } \\
\text { to time of highest } \\
\text { temperature (min) }\end{array}$ & $170.8 \pm 35.1$ & $204.1 \pm 38.5$ & $198.7 \pm 42.9$ & $171.8 \pm 30.3$ & $178.6 \pm 33.6$ & $181.1 \pm 23.0$ & NS \\
\hline Ambient temperature & $26.4 \pm 0.16$ & $26.7 \pm 0.14$ & $26.5 \pm 0.16$ & $26.5 \pm 0.16$ & $26.5 \pm 0.15$ & $26.4 \pm 0.15$ & NS \\
\hline
\end{tabular}

All values represent mean $\pm \mathrm{SEM}^{\circ} \mathrm{C}$ unless otherwise indicated. Abbreviations are the same as in Table 1.

have been reported to decrease serotonin turnover in the dorsal raphe and various projection sites (Nishikawa and Scatton 1985) and to potentiate the inhibitory effects of gamma-aminobutyric acid on neuronal firing on the dorsal raphe (Gallagher 1978). Insofar as electrolytic lesions of the dorsal raphe (Jouvet and Renault, 1966) or depletion of serotonin with parachlorophenylalanine (Pujol et al. 1971) acutely decrease sleep, it seems likely that the triazolam effects seen here are a result of druginduced inhibition of dorsal raphe activity. These findings are also consistent with a recent study in cats in which diathermocoagulation lesions of the central superior raphe nucleus resulted in decreased non-REM sleep (Arpa and de Andres 1993).
To assess the possibility that triazolam's effects on sleep might indirectly result from drug-induced alterations in temperature, we followed core temperature in all animals. There were no significant effects, suggesting that this particular explanation is unlikely. It is always possible, of course, that more subtle local changes in hypothalamic temperature are occurring, and this will be the subject of future investigation. It should also be noted that, in contrast to our microinjection work in the medial preoptic area (Mendelson and Monti, 1992), there was no evidence that the act of injection itself (even of vehicle) might induce transient core temperature changes.

We have previously reported that nifedipine ad-

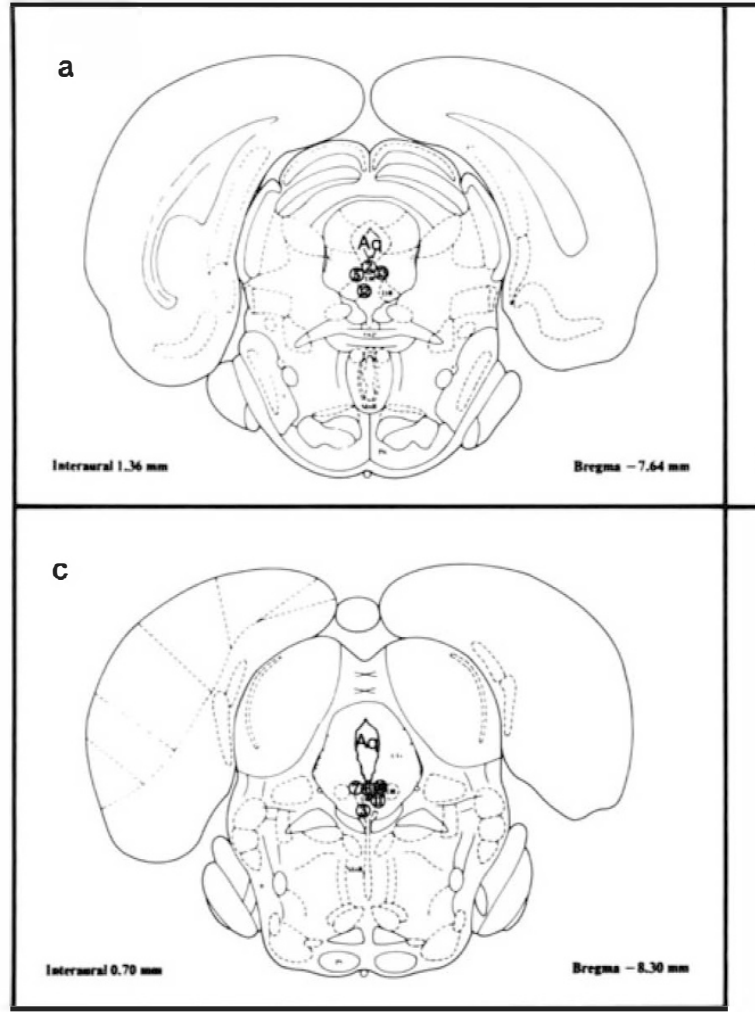

b

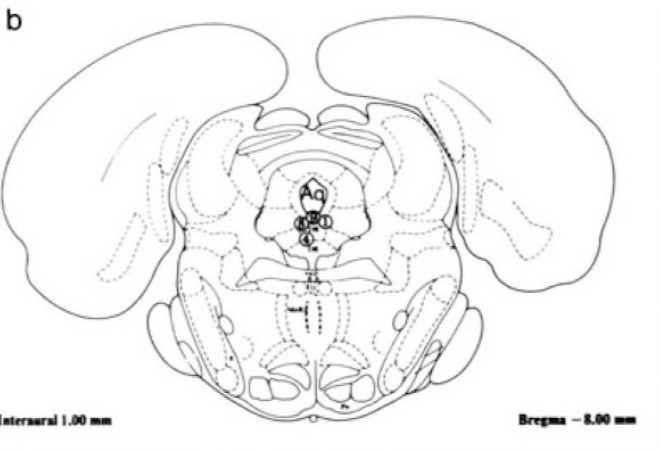

Figure 1. Sites of injection of triazolam and nifedipine in 13 rats. 
ministered intraventricularly blocks sleep induction by flurazepam injected systemically (Mendelson et al. 1984) and that comicroinjection of nifedipine into the medial preoptic area prevents sleep enhancement by triazolam injected locally (Mendelson and Monti 1992). Voltage-dependent calcium channels are found in many excitable tissues (Reborn and Gonzales 1988) and may be involved in various functions including pacemaking in autorhythmic cells. Binding sites for dihydropyridines such as nifedipine, which may be markers of one class of these channels, are found regionally in the central nervous system on neuronal cell bodies (Sanna and Hanbauer 1986). Calcium channels have been linked to central benzodiazepine receptors (Hirsch and Kochran, 1982), and the affinity of some benzodiazepines to the type II receptor has been reported but not yet confirmed to be sensitive to calcium ion concentrations (Lo et al. 1983). The present sleep study and the two previous reports on systemic flurazepam and triazolam microinjected into the medial preoptic area support the view that the mechanism by which these benzodiazepines alter sleep may involve alterations in voltage-dependent calcium channel function.

\section{ACKNOWLEDGMENT}

The author thanks Ms. Klara Velinzon and Mr. John DeMarco for technical assistance and Ms. Beth Robin for editorial assistance. This study was partially supported by National Science Foundation Grant BNS8919229 and a grant from the Upjohn Co.

\section{REFERENCES}

Arpa J, de Andres I (1993): Re-examination of the effects of raphe lesions on the sleep/wakefulness cycle states of cats. J Sleep Res 2:96-102

Gallagher DW (1978); Benzodiazepines: Potentiation of a GABA inhibitory response in the dorsal raphe nucleus. Eur J Pharmacol 49:133-143

Hirsch JD, Kochran RL (1982): Coupling at putative calcium channels with brain benzodiazepine receptors. Soc Neurosci Abstr 8:574

Jouvet M, Renault J (1966): Insomniepersistente après lesions des noyaux raphe chez le chat. Compt Rend Soc Biol 160:1461-1465

LoMMS, Nichoff DB, Kuhar MJ, Snyder SH (1983): Differen- tial localization of type I and II benzodiazepine binding sites in substantia nigra. Nature 306:57-60

Mendelson W, Guthrie R, Frederick G, Wyatt RJ (1974): Evaluation of the "Flower Pot Method" of REM sleep deprivation. Pharmacol Biochem Behav 2:553-556

Mendelson WB, MaJchrowicz E, Mirmirani N, Dawson S, Gillin JC, Wyatt RJ (1978): Sleep during chronic ethanol administration and withdrawal in rats. J Stud Alcohol 39:1213-1223

Mendelson WB, Skolnick P, Martin JV, Luu MD, Paul SM (1984): Diazepam-stimulated increases in the synaptosomal uptake of $45 \mathrm{Ca}^{++}$. Reversal by dihydropyridine calcium channel antagonists. Eur J Pharmacol 104:181-183

Mendelson WB, Martin JV, Wagner R (1986): A calcium channel agonist potentiates hypnotic effects of flurazepam. Sleep Res 15:38 (Abstract)

Mendelson WB, Martin JV, Perlis M, Wagner R(1987): Arousal induced by injection of triazolam into the dorsal raphe nucleus of rats. Neuropsychopharmacology 1:85-88

Mendelson WB (1992): Neuropharmacology of sleep induction by benzodiazepines. Crit Rev Neurobiol 16:221-232

Mendelson WB, Monti D (1992): Effects of triazolam and nifedipine injections into the medial preoptic area of the rat. Neuropsychopharmacology 8:227-232

Nagel JA, Satinoff E (1980): Mild cold exposure increases survival in rats with medial preoptic lesions. Science 208:301-303

Nishikawa T, Scatton B (1985): Inhibitory influence of GABA on central serotonergic transmission: involvement of the habenulo-raphe pathways in the GABAergic inhibition of ascending cerebral serotonergic neurons. Brain Res 331:81-90

Paxinos G, Watson C(1982): The Rat Brain in Stereotaxic Coordinates. New York: Academic Press.

Pujol JF, Buguet A, Froment JL, Jones B, Jouvet M (1971): The central metabolism of serotonin in the cat during insomnia: A neurophysiological and biochemical study after p-chlorophenylalanine or destruction of the raphe system. Brain Res 29:195-212

Raeburn D, Gonzales RA (1988): CNS disorders and calcium antagonists. Trends Pharmacol Sci 9:117-119.

Sainati SM, Lorens SA (1982): Intra-raphe benzodiazepines enhance rat locomotor activity: Interactions with $\mathrm{GABA}$. Pharmacol Biochem Behav 18:407-414

Sanna E, Hanbauer I (1986): Evidence for a selective localization of voltage-sensitive $\mathrm{Ca}^{++}$channels in nerve cell bodies of corpus callosum. J Neurochem 47:1552-1557

Szymusiak R, Satinoff E (1984): Ambient temperature-dependence of sleep disturbances produced by basal forebrain damage in rats. Brain Res Bull 12:295-305. 